\title{
Effect of Ash on Oxygen Carriers for the Application of Chemical Looping Combustion to a High Carbon Char
}

\author{
A. Rubel*, Y. Zhang, K. Liu and J. Neathery \\ University of Kentucky, Center for Applied Energy Research, 2540 Research Park Drive, Lexington, KY - USA \\ e-mails : rubel@caer.uky.edu -yizhang@caer.uky.edu - liv@caer.uky.edu - neathery@caer.uky.edu \\ * Corresponding author
}

\begin{abstract}
Résumé - Effet des cendres sur l'activité des porteurs d'oxygène dans la combustion du charbon en boucle chimique - L'application de la combustion en boucle chimique (CLC) aux combustibles solides est actuellement étudiée à l'Université du Kentucky, au Centre de Recherche de l'Energie Appliquée (CAER) dans le but de développer un procédé de gazéification/combustion en boucle chimique pressurisé $(\mathrm{PCLC} / \mathrm{G})$ afin de générer de l'électricité à partir de charbon. Un des principaux aspects de la combustion en boucle chimique de combustibles solides est la compréhension de l'effet des cendres sur la réactivité des porteurs d'oxygène (OCs). L'effet des cendres sur la capacité de transfert d'oxygène et sur l'aptitude à oxyder le charbon est étudié avec deux porteurs d'oxygène à base d'oxydes de fer. Les cendres utilisées sont des cendres volantes provenant d'une centrale thermique au charbon. Les expériences sont réalisées dans un système composé d'une thermo-balance couplée à un spectrographe de masse (TGMS) dans lequel on utilise d'abord $500 \mathrm{mg}$ d'un mélange de cendres/porteurs d'oxygène à différentes concentrations de cendres allant jusqu'à $75 \%$. Le gaz réducteur est composé de $10 \%$ de $\mathrm{H}_{2}, 15 \%$ de $\mathrm{CO}, 20 \%$ de $\mathrm{CO}_{2}$ et de $55 \%$ de $\mathrm{Ar}$; et le gaz oxydant est composé de $20 \%$ de $\mathrm{O}_{2}$ dans Ar. Les réactions d'oxydation/réduction sont quasi totales. D'après ces expériences, les cendres ont une activité propre de porteur d'oxygène, liée à la présence de fer dans les cendres, confirmée par les analyses DRX. Cela génère une augmentation du gain ou de la perte de masse du mélange pendant l'oxydation/réduction. Les vitesses d'oxydation/réduction augmentent avec la concentration des cendres à cause de l'augmentation de la porosité du mélange de porteurs d'oxygène avec les cendres, ce qui permet un meilleur accès des gaz réactifs sur les sites actifs des porteurs d'oxygène. Dans un deuxième temps, les deux porteurs d'oxygène sont utilisés pour brûler le charbon dans le TGMS avec comme seul apport d'oxygène celui du porteur d'oxygène. Le mélange de départ est composé de $10 \%$ de charbon et de $90 \%$ d'un des deux porteurs d'oxygène étudiés. Le matériel restant contenant le porteur d'oxygène réduit et les cendres/fumées est ensuite ré-oxydé puis $10 \%$ de charbon frais sont ajoutés au mélange résiduel avant une nouvelle réduction. Cette procédure est répétée durant 5 cycles en augmentant la concentration des cendres de 5 à $25 \%$ dans le mélange char/cendres/porteur d'oxygène. La conversion du carbone observée pendant ces essais est de 92 à 97,8 \% et de 97,3 à 99,7 \% selon le porteur d'oxygène utilisé. Les cendres ne sont pas nuisibles à l'activité des porteurs d'oxygène, et les deux porteurs d'oxygène réagissent correctement. Les résultats sont donc prometteurs pour l'application de la combustion en boucle chimique aux combustibles solides.
\end{abstract}

Abstract - Effect of Ash on Oxygen Carriers for the Application of Chemical Looping Combustion to a High Carbon Char - The application of Chemical Looping Combustion (CLC) to solid fuels is being investigated at the University of Kentucky, Center for Applied Energy Research (CAER) with the aim of 


\begin{abstract}
the development of a Pressurized Chemical Looping Combustion/Gasification (PCLC/G) process for the generation of electricity from coal. One important aspect of the CLC of solid fuel is the understanding of the effect of ash on the reactivity of Oxygen Carriers (OCs). The effect of ash on the redox capabilities of two different iron oxide OCs and on their ability to oxidize coal char was studied. To determine the effect of ash on the reactivity and recycle of the OCs through multiple redox cycles, fly ash from a coal-fired power plant was used. These experiments were performed in a TGMS system using $500 \mathrm{mg}$ of ash/OC mixtures containing different ash concentrations up to $75 \%$. The reducing gas was composed of $10 \% \mathrm{H}_{2}$, $15 \% \mathrm{CO}, 20 \% \mathrm{CO}_{2}$, and a balance of $\mathrm{Ar}$ and the oxidizing gas was $20 \% \mathrm{O}_{2}$ in Ar. Oxidation/reductions were carried to near completion. The ash was found to contain OC activity related to inherent iron present in the ash confirmed by XRD. This resulted in increased weight gain/loss on oxidation/reduction. The rate of oxidation/reduction increased with ash concentration due to increased porosity of the OC/ash mixture and better access of the reactive gases to the OC target sites. The two OCs were then used to combust a beneficiated coal char in the TGMS with the only oxygen supplied by an iron oxide OC. The starting mixture was $10 \%$ char and $90 \%$ of one of two OCs studied. The spent material containing reduced $O C$ and ash was re-oxidized and 10\% more char was added for a second reduction of the OC and oxidation of the added char. This procedure was repeated for 5 cycles increasing the ash concentrations from 5 to $25 \%$ in the char/ash/OC mixture. Carbon removal was 92 to 97.8 and 97.3 to 99.7\% for the two different iron oxide OCs tested. Ash was not detrimental to the activity of the OCs and both OCs performed well. The results were promising for the application of CLC directly to solid fuels.
\end{abstract}

\section{INTRODUCTION}

Chemical Looping Combustion (CLC) is proving to be a promising technology for the combustion of carboneous fuels producing a sequestration-ready concentrated $\mathrm{CO}_{2}$ stream without costly purification [1]. CLC's potential is two-fold in that it can provide a high-purity, sequestration-ready stream of $\mathrm{CO}_{2}$ and theoretically provide a substantial improvement in thermal conversion efficiency relative to conventional energy conversion technologies with other $\mathrm{CO}_{2}$ control processes such as amine scrubbing and oxy-combustion. However, most work to date has been the application of CLC to gaseous fuels [2-6]. Until recently the application of CLC to solid fuels involved a preliminary gasification step to produce a syngas composed of $\mathrm{CO}$ and $\mathrm{H}_{2}$ followed by CLC of the syngas [7-19].

Lately, there has been a considerable interest in the application of CLC directly to solid fuels [20-28]. Direct CLC of several solid fuels has been studied [25, 26]. A major problem with the direct CLC of solid fuels is the slow solid solid reaction rate which has lead to the proposal of Chemical Looping Oxygen Uncoupling (CLOU) [26, 29, 30]. In this variation of CLC, oxides of $\mathrm{Cu}, \mathrm{Mn}$, and $\mathrm{Co}$ under appropriate thermodynamic conditions release gas phase $\mathrm{O}_{2}$ in the fuel reactor which then oxidizes the solid fuel at a gassolid reaction rate 50 times higher than a solid-solid reaction with an iron oxide based Oxygen Carrier (OC). Beside slow reaction rates for solid-solid reduction reactions, there are other complications of the application of CLC to solid fuels. Some of the issues are the reactivity of the OC, its durability, the ability to be separated from the fuel ash, and the effect of ash on the reactivity and stability of the OC. Several OCs have been studied for use with solid fuels [22-24, 27-29,
31, 32]. Though not specifically studied for solid fuels, the crushing strength of several OCs has also been investigated $[33,34]$. The ability to separate OCs from solid fuel ash and the effect of ash on the OC needs study.

Recent work at the University of Kentucky, Center for Applied Energy Research, has been the understanding of the effect of ash on the OC and the maintenance of reactivity through multiple oxidation/reduction cycles in the presence of ash. Previous work at CAER indicated that iron oxide powder and catalysts were the best candidates for use as OCs for CLC of solid materials from those tested. They did not agglomerate; are relatively inexpensive; retained activity; and remained durable through multiple oxidation - reduction cycles. The results suggested that access of oxidizing reducing gases to the active sites of the $\mathrm{OC}$ through adequate porosity was important. It was found that increased $\mathrm{H}_{2}, \mathrm{CO}$ concentrations resulted in increased reduction rate for the iron oxides which may prove useful in a CLC process for solid materials as it provides a method to control the reduction rate during processing. $\mathrm{Fe}_{2} \mathrm{O}_{3}$ powder was used to directly combust a beneficiated coal char which contained $47 \%$ carbon. A mixture of $\mathrm{Fe}_{2} \mathrm{O}_{3}$ : char (90:10) heated to $950^{\circ} \mathrm{C}$ in Argon resulted in $88 \%$ removal of the carbon with the $\mathrm{OC}$ as the only source of oxygen. When $50 \%$ ash was added to the mixture of $\mathrm{Fe}_{2} \mathrm{O}_{3}$ /char, maintaining the same molar ratio of carbon to OC, carbon removal was $73 \%$ suggesting a detrimental effect of the ash [27, 35]. The purpose of this work was to expand on the previous study to determine the effect of higher concentrations of fly ash on the reactivity of two of the iron oxide Oxygen Carriers previously studied at the CAER. The effect of concentrations of fly ash from a coal-fired power plant to $75 \%$ on the reactivity and extent of oxidation/reduction of these OCs was 
studied by TG/MS. The ability of these OCs to oxidize a high carbon coal char with concentrations of fly ash to $75 \%$ and the effect of ash on the recycle potential of the OCs after reduction by the char was part of this study.

\section{MATERIALS AND METHODS}

\subsection{Effect of Ash on Redox of OCs Experimental}

Two iron oxide catalysts as OCs, Wustite and fused iron, and a fly ash from a Kentucky coal-fired power plant were used during this work. The two OCs and the fly ash were characterized by elemental analysis and XRF. The OCs were mixed with the fly ash in the following ratios of OC to Ash: 100:0, 75:25, 50:50, 25:75, and 0:100. A Netzsch Jupiter 449C thermal analyzer-mass spectrometer (TGMS) was used for oxidation/reduction cycles of the OCs, OC/ash mixtures, and the ash. The TGMS was fitted with a multiple gas mixing/controlling system comprised of 5 mass flow controllers (valves and controllers), a Lab View control system (software and interfaces), and three-way switching valves. This system could be operated unattended continuously through multiple oxidation - reduction cycles. Oxidation/ reductions were all carried out to near completion at $950^{\circ} \mathrm{C}$ for a minimum of 5 cycles. All samples were oxidized first followed by reduction. The gas flow rate through the TG was $200 \mathrm{~mL} / \mathrm{min}$ metered at standard conditions. The oxidizing gas was $20 \% \mathrm{O}_{2}$ in a balance of Ar. The reducing gas composition was $10 \% \mathrm{H}_{2}, 15 \% \mathrm{CO}, 20 \% \mathrm{CO}_{2}$, balance Ar. A 5 minute purge of Ar was used between oxidation and reduction. Weight gain/loss and maximum rates during oxidation/reduction were determined and corrected to $100 \%$ OC basis for comparison, i.e. for example, the weight loss for a 50:50 OC/ash sample was multiplied by 2 for comparison to $100 \%$ OC. Representative samples taken before and after redox were subjected to BET and pore size analysis. The MS was operated in a multiple ion detection mode (MID) for the following mass ions: $2\left(\mathrm{H}_{2}\right), 4$ (He, TG protective gas), $12\left(\mathrm{CO}, \mathrm{CO}_{2}\right), 14$ (N, used to verify that 28 was $\mathrm{CO}$ and not $\left.\mathrm{N}_{2}\right), 16\left(\mathrm{O}_{2}\right), 17$ and $18\left(\mathrm{H}_{2} \mathrm{O}\right), 28(\mathrm{CO}), 32\left(\mathrm{O}_{2}\right) 40(\mathrm{Ar}$, purge and balance gas), and $44\left(\mathrm{CO}_{2}\right)$. Since the current research is mainly focusing on the characteristics of OCs in the redox cycle and redox gases were in concentration and flux far in excess of gases from the samples studied, the MS was used mainly to verify redox gas concentration and complete purging between oxidation and reductions. The mass ions for $\mathrm{SO}_{2}$ and $\mathrm{H}_{2} \mathrm{~S}$ were not included in the MID parameter file, i.e. not determined since the concentration of sulfur in the ash was low at $0.25 \%$ weight, no sulfur gases were included in the redox gases, and no notable OC deactivation was observed. Figure 1 shows a typical TGMS profile showing all the mass ions determined for a five redox cycle run for Wustite/ash (75/25). In order to be able to clearly see the MS

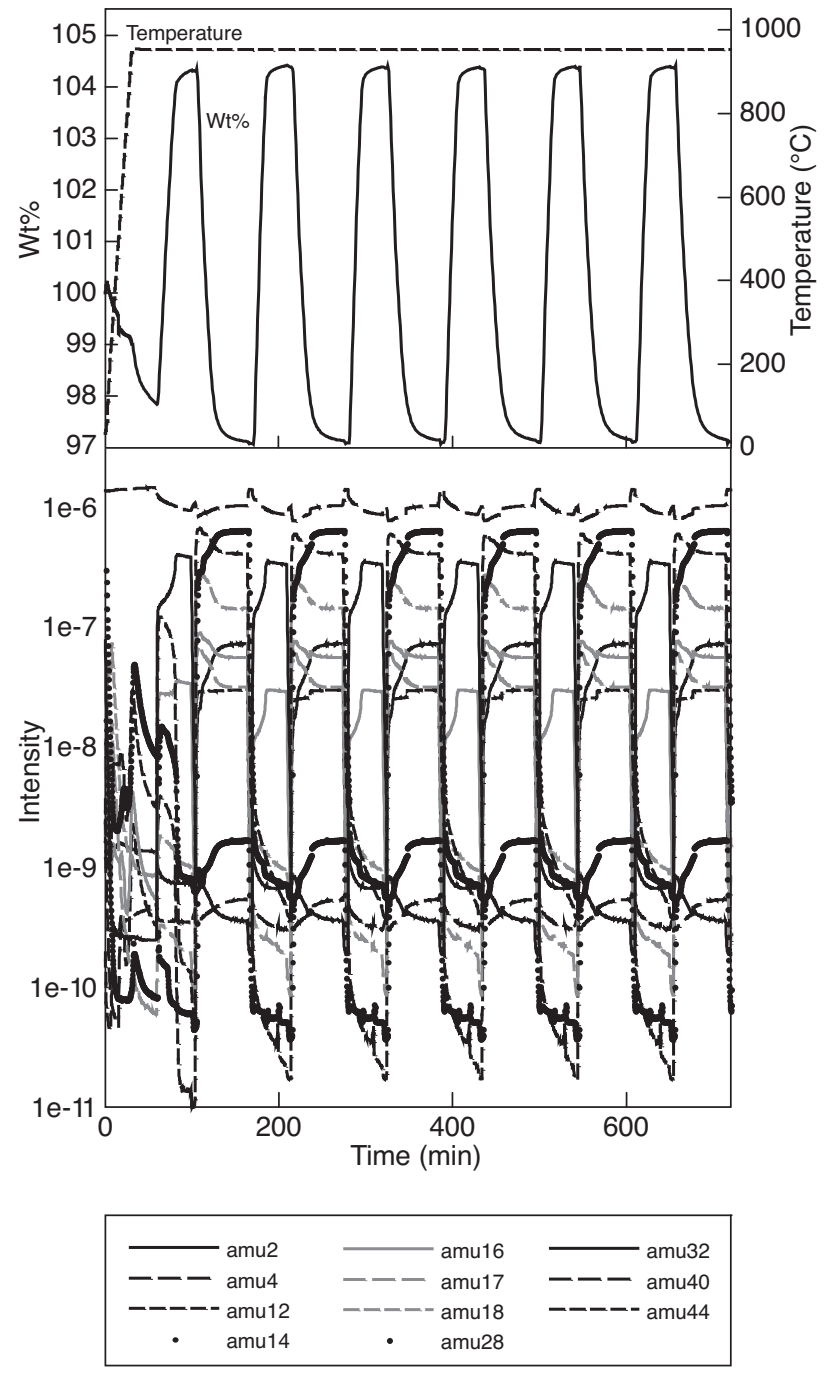

Figure 1

Complete 5 cycle TGMS profile of a Wustite/ash (75:25) run.

results from Figure 1, Figure 2 shows one redox cycle and only the major mass ions for the gases determined.

\subsection{Effect of Ash on CLC of a High Carbon Char Experimental}

A starting mixture of 1 part char and 9 parts of one of the two OCs studied (fused iron and Wustite) was blended using a mortar and pestle and placed in the sample crucible of the TGMS. The sample was heated at $950^{\circ} \mathrm{C}$ under a purge of $\mathrm{Ar}$ until no further weight loss was detected by the TG. The spent material containing reduced $\mathrm{OC}$ and ash was reoxidized using $20 \% \mathrm{O}_{2}$ in Ar. Besides the weight gain/loss during oxidation/reduction, the maximum rates of oxidation/ reduction were determined using the differential of the 


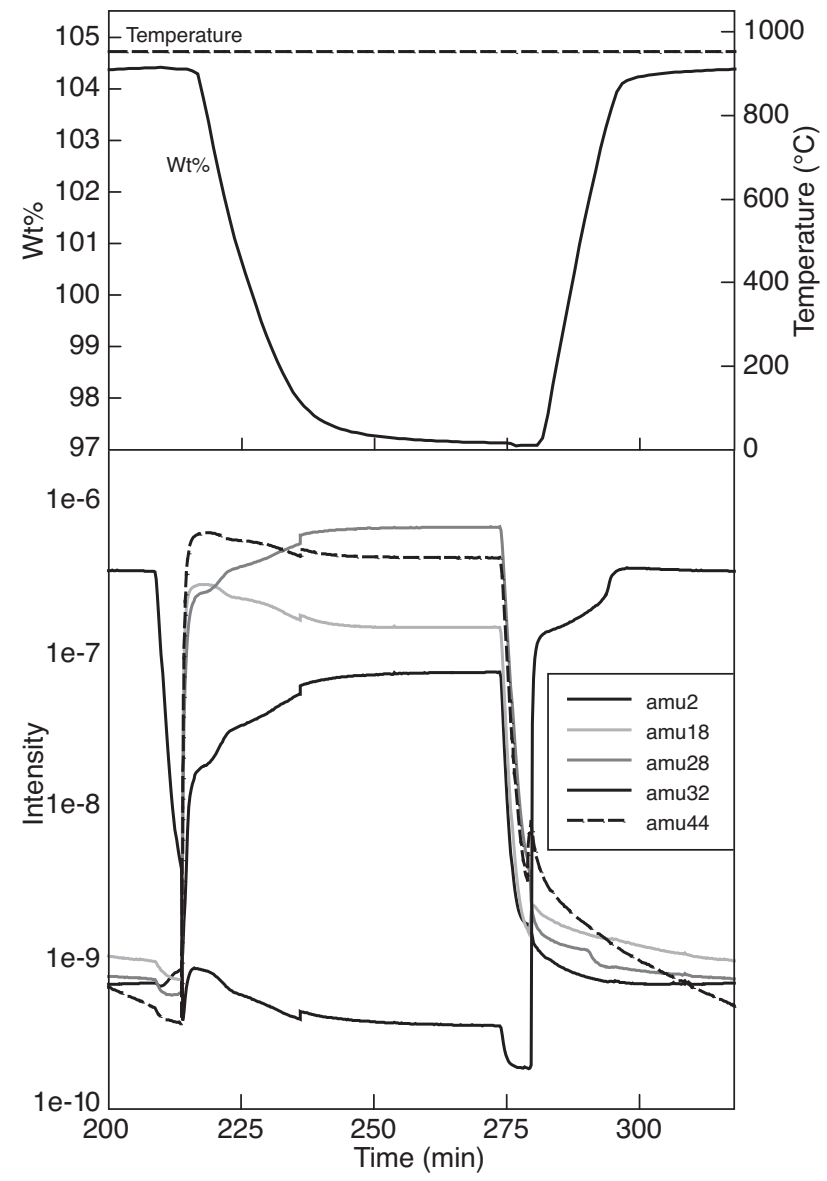

Figure 2

TGMS of one redox cycle from Figure 1 showing major mass ions for gases detected.

weight gain/loss curves of the TG. The sample was cooled and $10 \%$ more char was added using the mortar and pestle mixing method for a second reduction of the OC and oxidation of the added char. This procedure was repeated for 5 cycles increasing the ash concentrations from 5 to $25 \%$ of the ash/OC mixture at the end. Before and after each reduction cycle, aliquots of the before and spent mixtures were taken for carbon analysis to determine the starting carbon content and the carbon removed by the oxygen from the OC. Due to the constraints imposed by the size of the sample holder of the TG which allowed only 5 cycles of the above procedure before all sample was utilized for carbon analysis, surface areas and pore measurements were not done on these samples. Though surface areas and pore measurement are none destructive procedures, the time involved in the submission and return of results before being able to use the aliquot submitted for these measurement was considered excessive and would subject the sample to possible changes due to handling and exposure to atmospheric conditions.
In order to determine the effect of ash at higher concentrations on the ability of the OC to burn the char, two mixtures of char: OC: ash were made using a ball mill to thoroughly blend the mixes. These mixtures were 1:9:10 and 1:9:30 maintaining the same char to OC ratio but increasing the ash concentration. One redox cycle as described above was done on each mixture with aliquots of the before, after reduction and after oxidation mixtures subjected to carbon analysis. This approach to the study of higher ash concentration was necessary due to the limitation imposed by the sample holder of the TG which allowed only 5 cycles of the above procedure before all sample had been utilized for carbon analyses.

The MS MID profile used for the ash/OC/char study was the same as the ash/OC study. The sulfur content of the mixtures calculated from the analysis of the individual components was a maximum of $0.4 \%$ weight and since sulfur was not a focus of this study, sulfur gases were not determined. In the future the mass ions for sulfur gases will be included into the MS MID when high sulfur char is used.

\section{RESULTS AND DISCUSSION}

\subsection{Effect of Ash on Redox of OCs}

The materials used in this study, two iron oxide catalysts as OCs, Wustite and fused iron, and a fly ash from a Kentucky coal-fired power plant were characterized by XRF and elemental analysis. XRF analysis of the ash indicated it contained mostly quartz and aluminosilicate with a small amount of $\mathrm{Fe}_{2} \mathrm{O}_{3}$. The XRF analysis was qualitative so quantitative amounts were not known. The ash also contained $6.22 \% \mathrm{C}, 0.05 \% \mathrm{H}, 0.25 \% \mathrm{~S}$ and $1.3 \% \mathrm{O}$. The elemental and $\mathrm{XRF}$ analysis suggested that $\mathrm{S}$ was present as $\mathrm{SO}_{4}$. Wustite and fused iron were primarily $\mathrm{FeO}$ and $\mathrm{Fe}_{3} \mathrm{O}_{4}$ respectively.

The OCs, OCs mixtures with fly ash, and the ash were subjected to oxidation/reduction cycles in the TGMS system and procedures described in the experimental Section 1.1. First step in oxidation/reduction cycling was always oxidation. Therefore all carbon in the ash should be removed during this first oxidation so the first oxidation results were discounted. The weight gain/loss on oxidation/reduction in response to the ash was similar for both OCs. The weight gain is related to the oxygen taken up by the OC and the weight loss corresponds to the oxygen release during reduction. Figures 3-5 show a plot of redox cycle ( $x$-axis) versus weight gain/loss ( $y$-axis). Corrected for dilution of the OC by the ash, the amount of weight gain and loss increased as the amount of ash increased (Fig. 3). This increase was most likely the result of the presence of $\mathrm{Fe}_{2} \mathrm{O}_{3}$ and $\mathrm{SO}_{4}$ in the ash contributing as OCs. Figure 4 gives the weight gain/loss from the redox of the ash alone which was $1.2 \%$ for both 

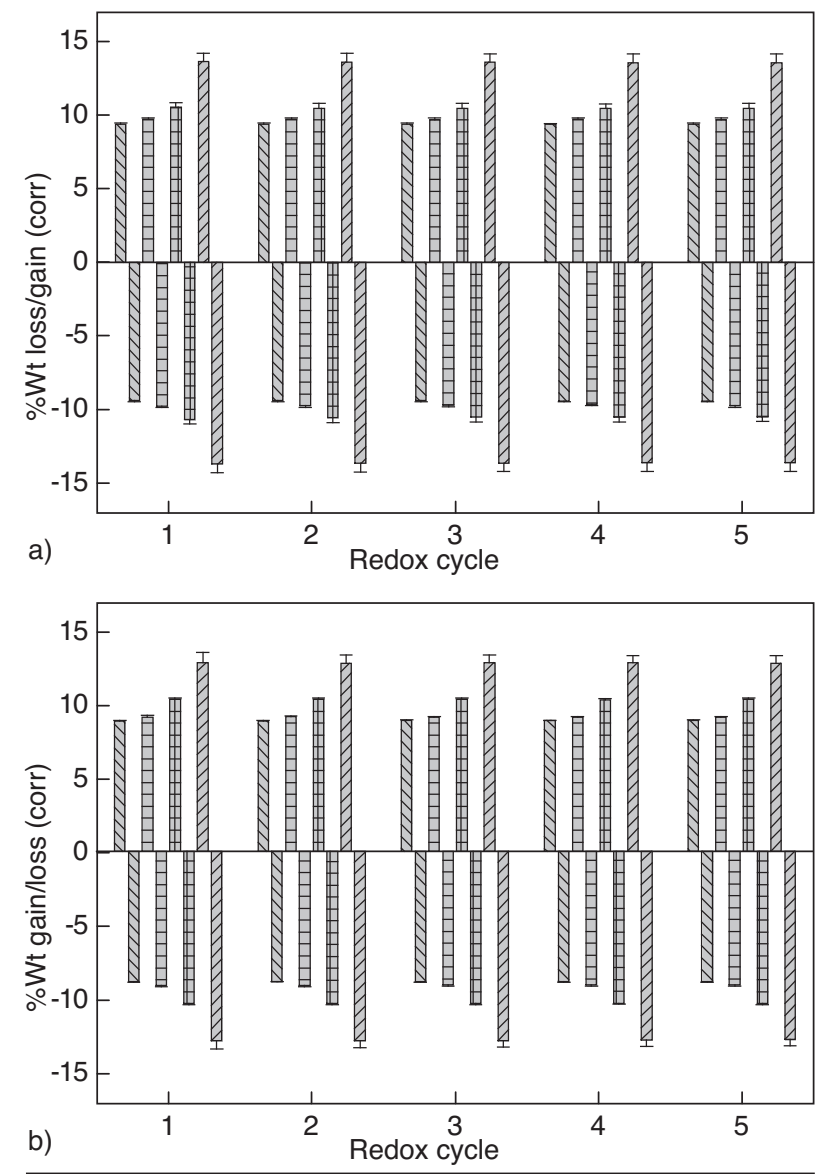

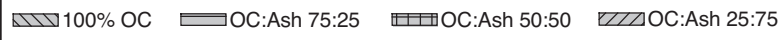

Figure 3

Effect of increasing ash concentrations on the weight gained and lost corrected for dilution by iron oxide based oxygen carriers. a) Wustite; b) fused iron.

oxidation and reduction. The data from Figure 3 corrected for weight loss related to the ash is given in Figure 5 suggested that ash had no detrimental effect on weight gain/loss on oxidation/reduction of the OCs. Again both OCs behaved the same. Additionally, there was an increase in the porosity of the pellet formed by the oxidation/reduction cycling of both Wustite and fused iron. With increasing ash, the pellet was more porous and more fragile. This was determined by visual inspection of the pellet formed and by the ease at which the pellet disintegrated on handling and confirmed by determining the surface area of the most fragile pellet compared with a pellet containing no ash (Tab. 1). Additionally, agglomeration was ruled out due to the fact that the pellet formed from the powder mixtures did not lose reactivity on repeated redox cycles. Our previous observations of OC agglomeration resulted in a pellet which appeared to be solid metal, was not fragile, and lost reactivity

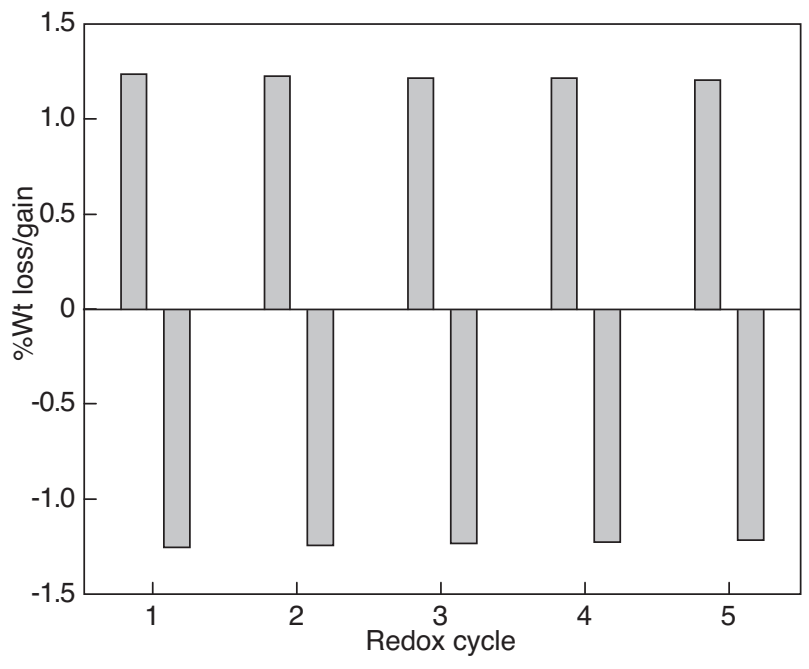

Figure 4

Weight loss/gain on oxidation/reduction of the ash used.

TABLE 1

Surface area and pore volume for spent fused iron and fused iron/ash mixture

\begin{tabular}{c|c|c|c}
\hline Sample & $\begin{array}{c}\text { BJH SA* } \\
\left(\mathrm{m}^{2} / \mathrm{g}\right)\end{array}$ & $\begin{array}{c}\text { BJH pore } \\
\text { vol }\left(\mathrm{m}^{3} / \mathrm{g}\right)\end{array}$ & $\begin{array}{c}\text { BET SA** } \\
\left(\mathrm{m}^{2} / \mathrm{g}\right)\end{array}$ \\
\hline 100\% Fused Fe & 0.0036 & 0.00014 & 0.0212 \\
\hline Fused Fe:ash (25:75) & 0.0427 & 0.00104 & 0.0699 \\
\hline
\end{tabular}

* Barrett, Joyner, Halenda method for surface area measurements.

** Brunauer, Emmett, Teller method for surface area measurements.

usually within one redox cycle. The fragility of the OC/ash mixture increased with increasing ash concentration. Dependant on the surface area measurement theory used, Barrett, Joyner, Halenda (BJH) or Brunauer, Emmett, Teller (BET), there was a 12 and 3 fold increase respectively in surface area between the spent $100 \%$ fused iron and spent 75:25 blend of ash with fused iron (Tab. 1). BJH pore volume increased 7 times with addition of ash. The increase in surface area and pore volume would result in increased access (penetration into the pellet) of reactive gases to the OC particles and more complete oxidation and reduction of the OC.

The maximum redox rates were determined from the peak values of the differential of the weight gain/loss curves from the TGMS experiments. The redox rates for Wustite and fused iron increased 4 and 3 fold respectively as the ash increased from 0 to $75 \%$ of the OCs (Fig. 6). Again both OCs tested behaved very similarly. The effect of ash to increase access of redox gases to active sites is most likely only important in the TG and may not be a consideration in a well mixed reactor such as a fluid bed. The TG was chosen 

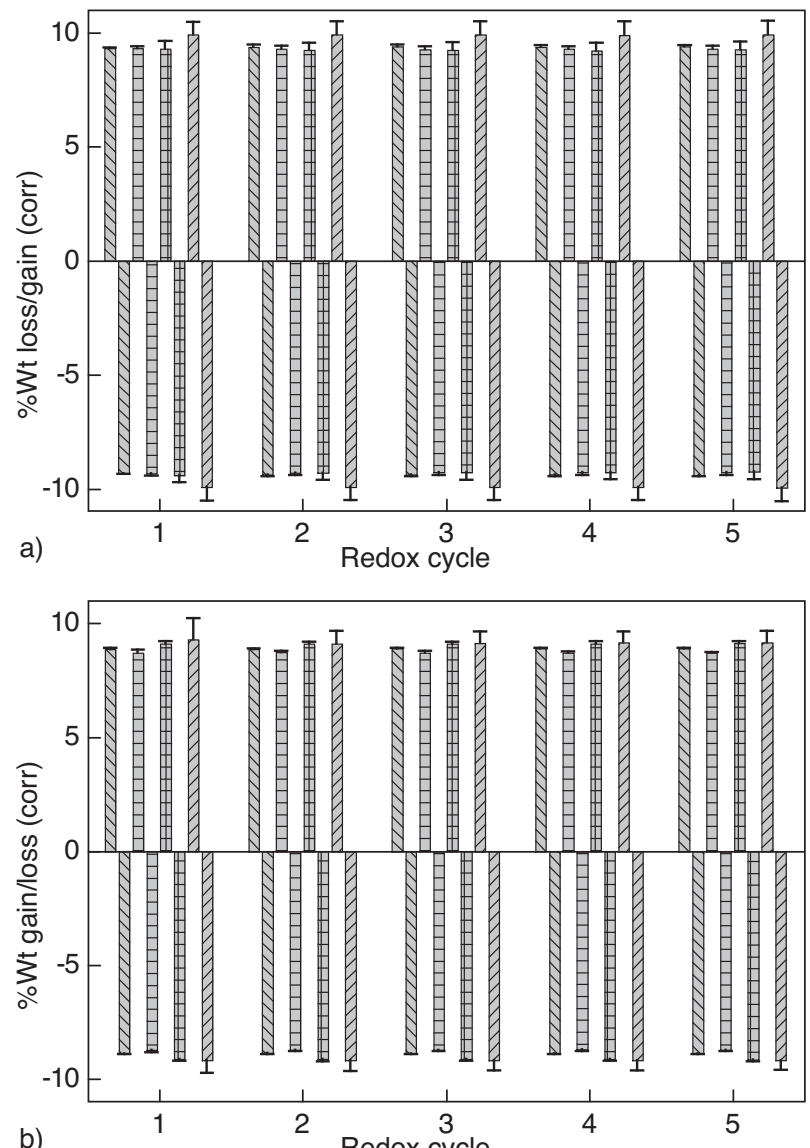

b)

100\% OC 75:25 OC:Ash 50:50 OC:Ash एय25:75 OC:Ash

Figure 5

The effect of increasing ash concentration on the weight gained/lost on oxidation/reduction corrected for dilution of the oxygen carrier and for the weight gained/lost due to the ash. a) Wustite; b) fused iron.
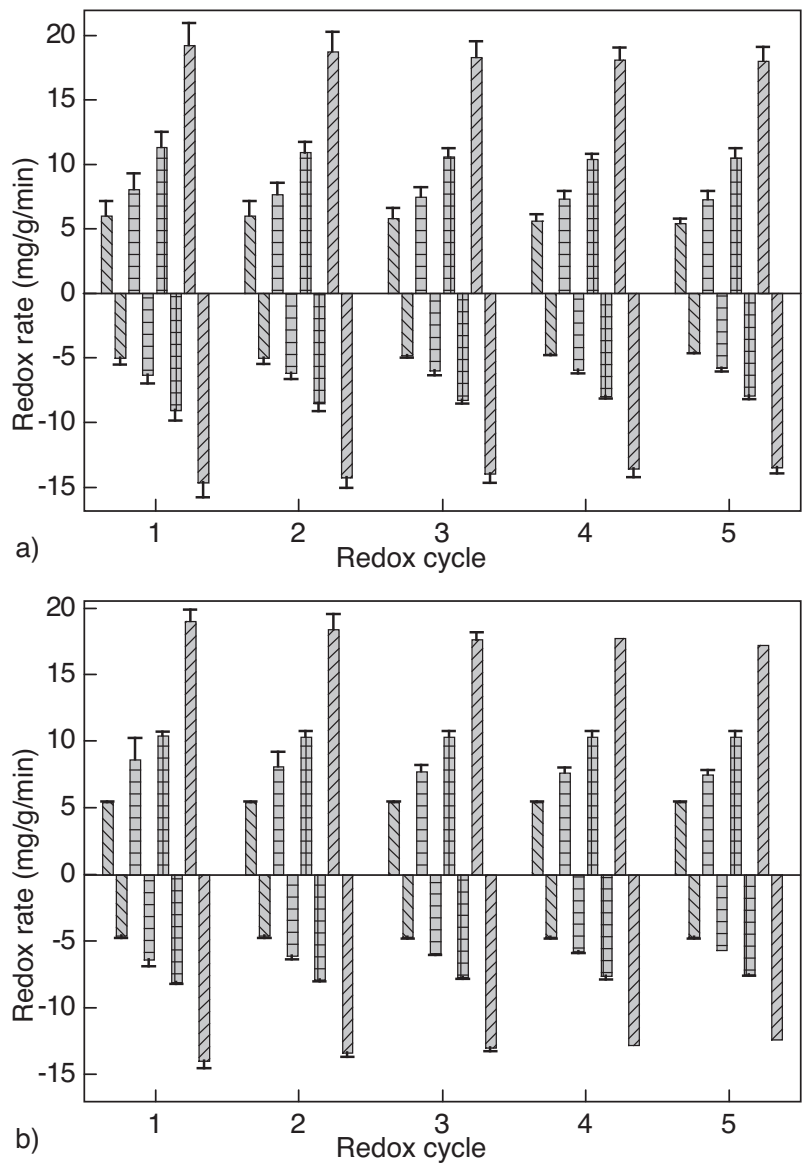

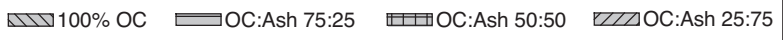

Figure 6

The effect of increasing ash concentration on the rates of oxidation/reduction corrected for dilution of the oxygen carrier and for the weight gained/lost due to the ash. a) Wustite; b) fused iron. for the initial screening and study of OCs and the effect of ash before running a continuous bench scale FB CLC reactor which is currently being commissioned at the University of Kentucky's CAER and which will be run using the OC chosen from the TG tests and will involve the CLC of a coal char providing ash. The use of TG for such screening is well established as valuable in the progression to larger scale testing. Bench scale testing is certainly not the final step in the development of the PCLC process but is an intermediate step just as the TG work is the first step. After bench scale testing a pressurized system will be developed to further investigate the effect of pressure.

\subsection{Effect of Ash on CLC of a High Carbon Char}

To study the ability of the OCs to oxidize a high carbon coal char in the presence of increasing ash concentrations mixtures of char and one of the two OCs (fused iron and Wustite) were blended using a mortar and pestle. The starting mixtures had a char to OC ratio of 1:9. After each redox cycle more char was added as indicated in the experimental Section 1.2 resulting in increasing ash concentration of the mixture from 5 to $25 \%$ since the beneficiated coal char contained $49.6 \%$ ash. The elemental analysis of the char indicated it contained $46.9 \% \mathrm{C}, 0.12 \% \mathrm{H}, 0.48 \% \mathrm{~N}, 2.23 \% \mathrm{~S}$, and $0.67 \% \mathrm{O}$.

Figures 7 and 8 show the results for the char carbon oxidation by the OCs. The starting carbon content (near right $y$-axis), carbon removed (left $y$-axis), and ash concentration (far right $y$-axis) in the mixtures for the 5 oxidation/reduction cycles ( $x$-axis) for the Wustite and fused iron OCs, respectively, are given. Both OCs performed well showing good carbon removal from the char and recycle capabilities. Carbon removal was 92 to $97.8 \%$ for Wustite (Fig. 7) and 

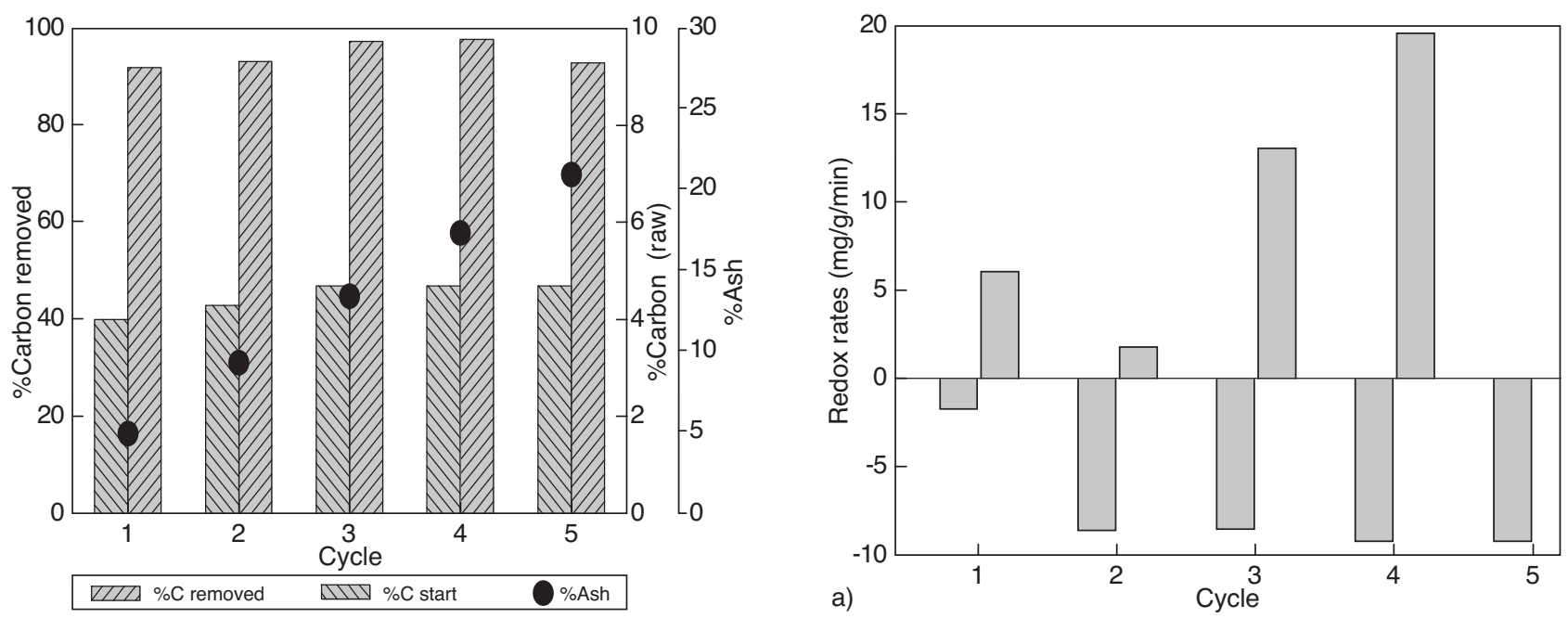

Figure 7

Combustion of a high carbon coal char with oxygen supplied by OC, Wustite.
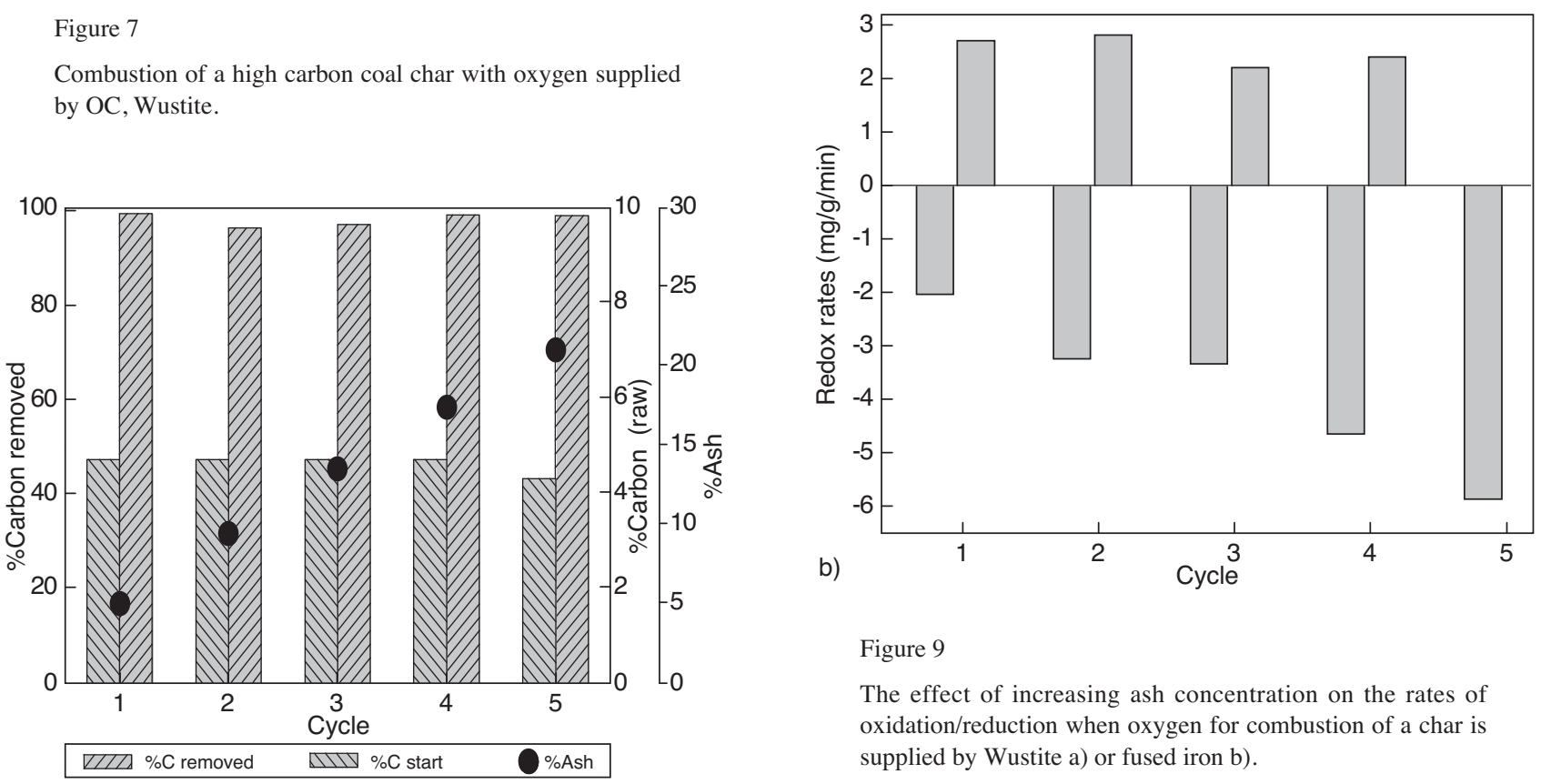

Figure 9

The effect of increasing ash concentration on the rates of oxidation/reduction when oxygen for combustion of a char is supplied by Wustite a) or fused iron b).

Figure 8

Combustion of a high carbon coal char with oxygen supplied by $\mathrm{OC}$, fused iron.

97.3 to $99.7 \%$ for fused iron (Fig. 8) indicating combustion of the carbon in the char by the oxygen supplied by the OC. Fused iron performed slightly better than Wustite with carbon removals above $99 \%$. The increase in ash concentration from 5 to $25 \%$ had no influence on the ability of the $\mathrm{OC}$ to oxidize the carbon and did not affect reoxidation of the OC.

The maximum redox rates determined from the peak value of the differential of the weight gain/loss curves were not consistent and showed different trends. As the ash/OC

work indicated, the rates of reduction/oxidation can increase significantly with increasing ash concentration under TG conditions. The results from this char study suggest that the same effect maybe occurring; however, the trends were not as consistent as the study using ash and OC only. Figure 9 show the results for the redox rates obtained during this study plotting redox cycle ( $x$-axis) versus redox rates ( $y$-axis). The results for Wustite suggest a large increase in the oxidation rate with cycle and increasing ash concentration (Fig. 9a). Reduction showed only a slight increase in rate. However, for fused iron, the reduction rate increased significantly and the oxidation rate appeared to remain the same (Fig. 9b). One possible explanation for these differences in the data is inconsistent blending of the mixtures with the mortar and 
pestle. This procedure was difficult and though care was taken to be consistent in the blending of the sample, it still was a very manual process. Direct solid-solid contact between char carbon and the OC was considered important in these experiments since the char lost only $16.1 \%$ of its carbon when run under the experimental conditions, $950^{\circ} \mathrm{C}$ and a purge of Ar, without the presence of an OC. Heating the char under Ar has been shown in previous work not to result in significant gasification of the char [35]. Though in cases where char gasification conditions exists such as under a $\mathrm{CO}_{2}$ or water vapor purge, then the primary mechanism would be considered gasification of the char carbon to syngas and combustion of the syngas by the $\mathrm{OC}$ but under an inert gas purge, significant gasification has been shown not to occur [35]. Ash could prevent this contact making uniform mixing of the char:OC:ash mixture extremely important not only during the mortar and pestle mixing but during sample loading of the TG to minimize any possible separation due to the different densities of the mixture components. Care was taken to mix the sample prior to loading the TG crucible. However, no uniform mixing could happen during the TG sample loading process due to the small sample size. To clarify and better understand the reaction rates under the study conditions, more work needs to be done and this work is continuing. Experimentation using the bench scale CLC reactor currently being built at the CAER should help define the effect of ash.

To study the effect of ash concentrations above $25 \%$, two char:fused iron:ash mixture were used which maintained a char to ash ratio of 10:90 and with ash concentration of 50 and $75 \%$. Char carbon oxidation by the $\mathrm{OC}$ was again studied in the TG under a purge of $\mathrm{Ar}$ at $950^{\circ} \mathrm{C}$.

Figure 10 shows the carbon removed, starting carbon concentration and the ash concentration. Since the ash contained 6\% carbon, the starting carbon was the sum of the char plus ash carbon and was determined by analytical analysis. As Figure 10 shows, carbon removals were 95 and $74 \%$ for the 50 and $75 \%$ ash mixtures respectively when they were run using an inert purge gas with the only source of oxygen the fused iron. These values of carbon removal were lower compared with the carbon combustion determined for lower concentrations of ash. This reduced combustion efficiency could be the result of both chemical and physical interactions between the components of the mixtures or most likely, considering the results from the OC/ash redox experiments, the high ash concentrations limiting contact between the OC and char carbon. This again is a function of the TG configuration which functions as a fixed bed and would not be a problem with a reactor such as a fluid bed where the OC and the fuel have a greater chance of contact even at high concentrations of ash. The use of an inert gas purge should not result in gasification of the char; only oxidation from solid-solid contact between the char and the OC.

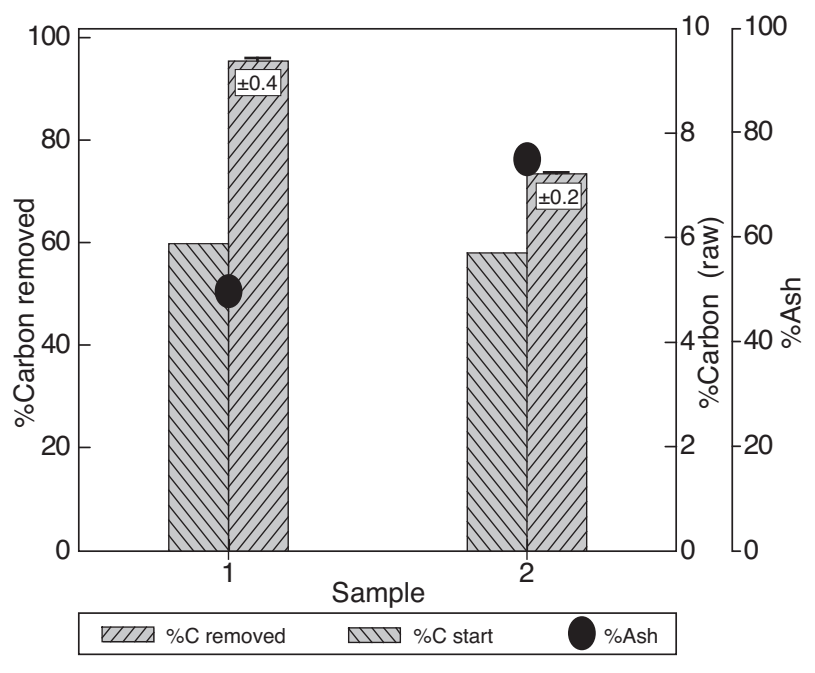

Figure 10

Effect of high ash concentrations on the combustion of a high carbon coal char.

\section{SUMMARY AND CONCLUSIONS}

This work was very encouraging for the use of iron oxide OCs for the direct CLC of solid fuels where high ash concentrations will be present. The ash was not detrimental to the reactivity of the two OCs studied and in fact it appeared that some components, $\mathrm{Fe}_{2} \mathrm{O}_{3}$ and $\mathrm{SO}_{4}$, in the ash may have functioned as OCs contributing to additional weight gain/loss on redox cycling. Both iron oxides though present as different forms, $\mathrm{FeO}$ and $\mathrm{Fe}_{3} \mathrm{O}_{4}$ produced the same results. The increase in the rates of redox with increased concentration of ash corresponded to increased porosity and surface area for the spent mixtures of OC/ash suggesting the importance of access to active sites for the reactive gases. In the TG sample holder, the spent material forms a pellet which limits the ability of gases to reach active sites. The effect of ash to improve access to these sites is likely a function of the TG configuration and a well mixed reactor such as a fluid bed would not necessarily produce the same effect.

The direct combustion of the carbon in a beneficiated coal char containing $47 \%$ carbon by the oxygen in the OCs was not affected by increasing ash concentration to $25 \%$. Nor did the ash affect the re-oxidation of the OCs. Carbon removals to $97.8 \%$ and $99.7 \%$ were obtained for Wustite and fused iron respectively with no relation to the increasing ash. Again both OCs behaved similarly in spite of being different iron oxides. The ash may have increased redox rates under the TG conditions similar to the ash/OC study. However, the results were not as consistent and this needs further study. The possibility of the ash increasing the surface area and porosity 
in the char oxidation study was not determined due to the sample size constraints of the TG sample holder.

Higher ash concentrations to $75 \%$ may have impeded the interactions between the char carbon and the $\mathrm{OC}$ and carbon oxidation using the $\mathrm{OC}$ as the only source of oxygen was lower but at $50 \%$ ash the OC still removed $95 \%$ of the carbon and only at $75 \%$ ash was carbon removal significantly lowered to $74 \%$. This might not be a problem in a well mixed reactor such as a fluid bed. Direct solid-solid contact between char carbon and the OC was considered important in these experiments since gasification of the char under the experimental conditions, an inert gas and $950^{\circ} \mathrm{C}$, has been previously shown not to occur [35].

\section{ACKNOWLEDGMENTS}

Funding for this work was provided by the Carbon Management Research Group: Big Rivers Electric Corporation, Duke Energy, East Kentucky Power Cooperative, E-ON US, Electric Power Research Institute, Illinois Clean Coal Institute, Kentucky Department of Energy Development and Independent, and Kentucky Power (AEP).

\section{REFERENCES}

1 Freund P. (1998) Abatement and Mitigation of Carbon Dioxide Emissions from Power Generation, Powergen 98 Conference, Milan.

2 Mattisson T., Johansson M., Lyngfelt A. (2004) Multicycle Reduction and oxidation of different types of iron oxide particles - application to chemical-looping combustion, Energ. Fuel. 18, 3, 628-637.

3 Ishida M., Jin H. (1994) A Novel Combustor Based on Chemical-looping Reactions and its Reaction Kinetics, J. Chem. Eng. Jpn 27, 296-300.

4 Ishida M., Jin H., Okamoto T.A. (1996) Fundamental Study of a New Kind of Medium Material for Chemical-looping Combustion, Energ. Fuel. 10, 4, 958-63.

5 Adanez J., de Diego L.F., Gayan P., Garcia-Labiano F., Gayan P., Abad A., Palacios J.M. (2004) Selection of Oxygen Carriers for Chemical-Looping Combustion, Energ. Fuel. 18, 2, 371-7.

6 Hossain M.M., de Lasa H.I. (2008) Chemical-Looping Combustion (CLC) for inherent $\mathrm{CO}_{2}$ separations - a review, Chem. Eng. Sci. 63, 18, 4433-4451.

7 Abad A., Adanez J., de Diego L.F., Gayan P., Garcia-Labiano F. (2007) Design of chemical-looping combustion systems using syngas - Application of $\mathrm{Cu}-, \mathrm{Fe}-$, and Ni-based oxygen carriers' reactivity, in 2007 International Conference on Coal Science and Technology, Nottingham, GB, 1P18.

8 Abad A., Garcia-Labiano F., de Diego L.F., Gayan P., Adanez J. (2007) Reduction kinetics of $\mathrm{Cu}_{-}, \mathrm{Ni}-$, and $\mathrm{Fe}-$ based oxygen carriers using syngas $\left(\mathrm{CO}+\mathrm{H}_{2}\right)$ for chemical-looping combustion, Energ. Fuel. 21, 4, 1843-1853.

9 Garcia-Labiano F., Adanez J., de Diego L.F., Gayan P., Abad A. (2006) Effect of Pressure on the Behavior of Copper-, Iron-, and Nickel-Based Oxygen Carriers for Chemical-Looping Combustion, Energ. Fuel. 20, 1, 26-33.
10 Garcia-Labiano F., de Diego L.F., Adanez J., Gayan P., Dueso C., Forero C.R. (2007) Operation of a 500 Wth Chemical Looping Combustion Plant using Syngas as Fuel, in 2007 International Conference on Coal Science and Technology, Nottingham, GB.

11 Gupta P., Velazquez-Vargas L.G., Fan L.S. (2007) Syngas Redox (SGR) to Produce Hydrogen from Coal Derived Syngas, Energ. Fuel. 21, 5, 2900-2908.

12 Leion H., Mattisson T., Lyngfelt A. (2007) The use of petroleum coke as fuel in chemical-looping combustion, Fuel 86, 12-13, 1947-1958.

13 Leion H., Mattisson T., Lyngfelt A. (2008) Solid fuels in chemical-looping combustion, Int. J. Greenhouse Gas Control 2 , $2,180-193$.

14 Li F., Kim H.R., Sridhar D., Wang F., Zeng L., Chen J., Fan L.S. (2009) Syngas Chemical Looping Gasification Process: Oxygen Carrier Particle Selection and Performance, Energ. Fuel. 23, 8, 4182-4189.

15 Mattisson T., García-Labiano F., Kronberger B., Lyngfelt A., Adánez J., Hofbauer H. (2007) Chemical-looping combustion using syngas as fuel, Int. J. Greenhouse Gas Control 1, 2, 158-169.

16 Scott S.A., Dennis J.S., Hayhurst A.N., Brown T. (2006) In situ gasification of a solid fuel and $\mathrm{CO}_{2}$ separation using chemical looping, AIChE J.52, 9, 3325-3328.

17 Siriwardane R., Poston J., Chaudhari K., Zinn A., Simonyi T., Robinson C. (2007) Chemical-Looping Combustion of Simulated Synthesis Gas Using Nickel Oxide Oxygen Carrier Supported on Bentonite, Energ. Fuel. 21, 3, 1582-1591.

18 Tian H., Chaudhari K., Simonyi T., Poston J., Liu T., Sanders T., Veser G.T., Siriwardane R. (2008) Chemical-looping Combustion of Coal-derived Synthesis Gas Over Copper Oxide Oxygen Carriers, Energ. Fuel. 22, 6, 3744-3755.

19 Xiang W., Wang S., Di T.T. (2008) Investigation of gasification chemical looping combustion combined cycle performance, Energ. Fuel. 22, 2, 961-966.

20 Cao Y., Casenas B., Pan W.P. (2006) Investigation of chemical looping combustion by solid fuels. 2. Redox reaction kinetics and product characterization with coal, biomass, and solid waste as solid fuels and $\mathrm{CuO}$ as an oxygen carrier, Energ. Fuel. 20, 5 , 1845-1854.

21 Cao Y., Pan W.P. (2006) Investigation of chemical looping combustion by solid fuels. 1. Process analysis, Energ. Fuel. 20, $5,1836-1844$.

22 Chuang S.Y., Dennis J.S., Hayhurst A.N., Scott S.A. (2008) Development and performance of $\mathrm{Cu}$-based oxygen carriers for chemical-looping combustion, Combust. Flame 154, 1-2, 109-121.

23 Leion H., Jerndal E., Steenari B.-M., Hermansson S., Israelsson M., Jansson E., Johnsson M., Thunberg R., Vadenbo A., Mattisson T., Lyngfelt A. (2009) Solid fuels in chemical-looping combustion using oxide scale and unprocessed iron ore as oxygen carriers, Fuel 88, 10, 1945-1954.

24 Leion H., Lyngfelt A., Mattisson T. (2009) Solid fuels in chemical-looping combustion using a NiO-based oxygen carrier, Chem. Eng. Res. Des. 87, 11, 1543-1550.

25 Leion H., Mattisson T., Lyngfelt A. (2008) $\mathrm{CO}_{2}$ capture from direct combustion of solid fuels with Chemical-Looping Combustion, in The Proceedings of the 33rd International Technical Conference on Coal Utilization and Fuel Systems, Clearwater, FL, USA.

26 Leion H., Mattisson T., Lyngfelt A. (2008) Combustion of a German lignite using Chemical-Looping with Oxygen Uncoupling (CLOU), in The Proceedings of 33rd International Technical Conference on Coal Utilization \& Fuel Systems, Clearwater, FL, USA. 
27 Rubel A., Lui K., Neathery J., Taulbee D. (2007) Evaluation of oxygen carriers for chemical looping combustion of coal and solid fuels, in 24th Pittsburgh Coal Conference, Johannesburg, SA, paper 21-1.

28 Siriwardane R., Tian H., Richards G., Simonyi T., Poston J. (2009) Chemical-Looping Combustion of Coal with Metal Oxide Oxygen Carriers, Energ. Fuel. 23, 8, 3885-3892.

29 Mattisson T., Leion H., Lyngfelt A. (2009) Chemical-looping with oxygen uncoupling using $\mathrm{CuO} / \mathrm{ZrO}_{2}$ with petroleum coke, Fuel 88, 4, 683-690.

30 Mattisson T., Lyngfelt A., Leion H. (2009) Chemical-looping with oxygen uncoupling for combustion of solid fuels, Int. J. Greenhouse Gas Control 3, 1, 11-19.

31 Zhao H., Liming L., Xu D., Chuguang Z. (2007) Study on Nibased Oxygen Carriers for Chemical Looping Combustion by Coal Char, in 24th International Pittsburgh Coal Conference, Johannesburg, SA, pp. 1-18.
32 Zhao H.B., Liu L.M., Wang B.W., Xu D., Jiang L.L., Zheng C.G. (2008) Sol-gel derived $\mathrm{NiO} / \mathrm{NiAl}_{2} \mathrm{O}_{4}$ oxygen carriers for chemical-looping combustion by coal char, Energ. Fuel. 22, 2, 898-905.

33 Jerndal E., Mattisson T., Lyngfelt A. (2009) Investigation of Different $\mathrm{NiO} / \mathrm{NiAl}_{2} \mathrm{O}_{4}$ Particles as Oxygen Carriers for Chemical-Looping Combustion, Energ. Fuel. 23, 2, 665-676.

34 Jerndal E., Mattisson T., Thijs I., Snijkers F., Lyngfelt A. (2009) $\mathrm{NiO}$ particles with $\mathrm{Ca}$ and $\mathrm{Mg}$ based additives produced by spray-drying as oxygen carriers for chemical-looping combustion, Energy Procedia 1, 1, 479-486.

35 Rubel A., Liu K., Neathery J., Taulbee D. (2009) Oxygen carriers for chemical looping combustion of solid fuels, Fuel $\mathbf{8 8}$, $5,876-884$

Final manuscript received in July 2010 Published online in February 2011 